\title{
Exposure to high concentrations of inspired oxygen does not worsen lung injury after cardiac arrest
}

Jonathan Elmer ${ }^{1,2,3}$, Bo Wang ${ }^{3}$, Samer Melhem ${ }^{4}$, Raghevesh Pullalarevu ${ }^{5}$, Nishit Vaghasia ${ }^{5}$, Jaya Buddineni², Bedda L Rosario ${ }^{6}$, Ankur A Doshi ${ }^{3}$, Clifton W Callaway ${ }^{1,3}$, Cameron Dezfulian ${ }^{1,2,7^{*}}$ and on behalf of the University of Pittsburgh Post-Cardiac Arrest Service (PCAS)

\begin{abstract}
Introduction: Post-cardiac arrest patients are often exposed to 100\% oxygen during cardiopulmonary resuscitation and the early post-arrest period. It is unclear whether this contributes to development of pulmonary dysfunction or other patient outcomes.

Methods: We performed a retrospective cohort study including post-arrest patients who survived and were mechanically ventilated at least 24 hours after return of spontaneous circulation. Our primary exposure of interest was inspired oxygen, which we operationalized by calculating the area under the curve of the fraction of inspired oxygen ( $\mathrm{FiO}_{2} \mathrm{AUC}$ ) for each patient over 24 hours. We collected baseline demographic, cardiovascular, pulmonary and cardiac arrest-specific covariates. Our main outcomes were change in the respiratory subscale of the Sequential Organ Failure Assessment score (SOFA-R) and change in dynamic pulmonary compliance from baseline to 48 hours. Secondary outcomes were survival to hospital discharge and Cerebral Performance Category at discharge.

Results: We included 170 patients. The first partial pressure of arterial oxygen (PaO2):FiO2 ratio was $241 \pm 137$, and $85 \%$ of patients had pulmonary failure and $55 \%$ had cardiovascular failure at presentation. Higher $\mathrm{FiO}_{2} \mathrm{AUC}$ was not associated with change in SOFA-R score or dynamic pulmonary compliance from baseline to 48 hours. However, higher $\mathrm{FiO}_{2} \mathrm{AUC}$ was associated with decreased survival to hospital discharge and worse neurological outcomes. This was driven by a $50 \%$ decrease in survival in the highest quartile of $\mathrm{FiO}_{2} \mathrm{AUC}$ compared to other quartiles (odds ratio for survival in the highest quartile compared to the lowest three quartiles 0.32 ( $95 \%$ confidence interval 0.13 to 0.79 ), $P=0.003)$.

Conclusions: Higher exposure to inhaled oxygen in the first 24 hours after cardiac arrest was not associated with deterioration in gas exchange or pulmonary compliance after cardiac arrest, but was associated with decreased survival and worse neurological outcomes.
\end{abstract}

\section{Introduction}

Over 500,000 Americans suffer a cardiac arrest (CA) annually [1]. Among those with return of spontaneous circulation (ROSC), 50 to $60 \%$ do not survive to hospital discharge [2,3]. The post-arrest syndrome develops commonly after $\mathrm{CA}$, and is characterized by multiple organ

\footnotetext{
* Correspondence: dezfulianc@upmc.edu

${ }^{1}$ Safar Center for Resuscitation Research, University of Pittsburgh School of Medicine, 100 Hill Building, 3434 Fifth Avenue, Pittsburgh, PA 15260, USA ${ }^{2}$ Department of Critical Care Medicine, University of Pittsburgh School of Medicine, Pittsburgh, USA

Full list of author information is available at the end of the article
}

dysfunction secondary to global ischemia-reperfusion injury and a systemic inflammatory response [4-6]. Pulmonary dysfunction and the acute respiratory distress syndrome (ARDS) are components of this process.

Observational studies have associated higher arterial oxygen concentration (hyperoxia) with worsened clinical outcomes [7-10]. Authors of these studies have hypothesized that this effect is mediated through worsening of secondary brain injury by increased oxidative stress and free radical formation, but other possible explanations for this association have not been previously 
explored. In the lung, oxygen exposure may to lead to ARDS through free-radical formation [11,12], and although isolated respiratory failure is an uncommon proximate cause of death after CA, lung dysfunction is common and may worsen patient outcomes [13]. Preclinical data suggest that high concentrations of oxygen cause pulmonary endothelial apoptotic cell death and worsened lung injury [14-17]. However, there is an important interaction between tidal volume (that is, stretch-induced lung injury) and oxygen toxicity that may explain this observation [18,19]. Indeed, early clinical reports of pulmonary oxygen toxicity were conducted when open-lung ventilation with high tidal volumes was standard practice [20-22].

CA patients are often exposed to $100 \%$ oxygen during cardiopulmonary resuscitation (CPR) and early after ROSC [10]. Thus, this cohort is theoretically at risk for oxygen-induced lung toxicity, which might help explain the association between hyperoxia and patient outcomes. Respiratory failure based on a higher sequential organ failure assessment (SOFA) score has been associated with increased mortality in two studies of CA outcomes $[23,24]$. We analyzed data from a high-resolution CA database to test the hypothesis that cumulative dose of inhaled oxygen to which patients are exposed after CA is associated with deterioration in lung function in the first $48 \mathrm{~h}$ after ROSC. Second, we tested the association between inhaled oxygen exposure and clinically relevant patient outcomes including survival to hospital discharge and neurological outcome.

\section{Materials and methods}

\section{Patients and setting}

We analyzed a prospective database of consecutive in- and out-of-hospital CA patients cared for at UPMC Presbyterian hospital by the Post-Cardiac Arrest Service (PCAS). UPMC Presbyterian is a 798-bed tertiary care center with approximately 54,000 emergency department visits annually and 150 ICU beds. The PCAS treats over 350 survivors of CA annually and is part of local efforts to regionalize and improve CA care. We have implemented hospital-wide protocols to standardize and improve post-CA care [25].

We included CA patients presenting between October 2008 (when electronic medical records were implemented system-wide, permitting recording of vital signs and ventilator data) and April 2010, who had a CA with ROSC, survived and were mechanically ventilated for a least $24 \mathrm{~h}$. We included both in- and out-of-hospital CA patients because 1) this reflects the true heterogeneity encountered in clinical practice, 2) we hypothesized that post-arrest organ dysfunction would be primarily dependent on ischemia and reperfusion injury rather than pathology present antecedent to the arrest, and
3) we have previously demonstrated that the affect of cardiopulmonary dysfunction on patient outcomes is stable across arrest location [23]. We excluded patients if the time of ROSC was unknown, if vital signs and vasopressor requirements were not recorded within $6 \mathrm{~h}$ of ROSC, or if arterial blood gas (ABG) or ventilator data were not recorded within $4 \mathrm{~h}$ of ROSC (we have previously reported that this is the timeframe during which patients are most often exposed to high fraction of inspired oxygen $\left(\mathrm{FiO}_{2}\right)$ levels [10]). We further excluded patients managed with extracorporeal membrane oxygenation. The University of Pittsburgh Institutional Review Board approved all aspects of this study with a waiver of informed consent.

\section{Primary exposure and covariates}

Our primary exposure of interest was inhaled oxygen. To quantify this exposure, we calculated the area under the curve (AUC) of the $\mathrm{FiO}_{2}\left(\mathrm{FiO}_{2} \mathrm{AUC}\right)$ for each patient as follows. First, we recorded $\mathrm{FiO}_{2}$ values hourly for $24 \mathrm{~h}$ after ROSC. Based on our local practice, we assumed all patients were ventilated with an $\mathrm{FiO}_{2}$ of 1.0 during their initial resuscitation until the first recorded value [10]. Next, we summed these hourly values to derive the $\mathrm{FiO}_{2} \mathrm{AUC}$. This $\mathrm{FiO}_{2} \mathrm{AUC}$ could theoretically range from 5 ( $24 \mathrm{~h}$ on room air at $\left.\mathrm{FiO}_{2}=0.21\right)$ to $24\left(24 \mathrm{~h}\right.$ on $\left.\mathrm{FiO}_{2}=1.0\right)$.

We abstracted demographic and basic clinical information from our prospective CA registry, including subject age, gender, location of arrest (out-of-hospital versus in-hospital), initial arrest rhythm (ventricular tachycardia or fibrillation (VT/VF) versus pulseless electrical activity (PEA) or asystole) and use of hypothermia. Additionally we abstracted each subject's Pittsburgh CA Category (PCAC). The PCAC is a clinical prediction tool that stratifies post-arrest patients by their risk of subsequent death or neurological deterioration based on clinical characteristics during the first $6 \mathrm{~h}$ after ROSC [23]. This tool divides patients into four categories that are strongly predictive of survival and functional outcome.

We assessed baseline post-arrest pulmonary dysfunction by recording each patient's initial partial pressure of arterial oxygen $\left(\mathrm{PaO}_{2}\right): \mathrm{FiO}_{2}$ (P:F) ratio and dynamic pulmonary compliance, which we calculated as equal to tidal volume/ (peak inspiratory pressure minus positive end-expiratory pressure (PEEP)). Additionally, we calculated the respiratory subscale of the SOFA scale (SOFA-R) [26]. To quantify the degree of post-arrest cardiovascular dysfunction, we calculated the baseline cardiovascular subscale of the SOFA score (SOFA-CV), cumulative vasopressor index (CVI), and shock index (mean arterial pressure/ heart rate). The SOFA score is a validated measure of organ dysfunction commonly used in critical care research [26]. The respiratory subscale assigns 0 to 4 points based on the P:F ratio and requirement for mechanical 
ventilation and the cardiovascular subscale assigns 0 to 4 points based on the presence of hypotension and vasoactive medication requirement. The CVI is a method of standardizing vasopressor dosing [26,27]. We calculated the CVI from the highest vasopressor dose needed to achieve a mean arterial pressure (MAP) $>70 \mathrm{mmHg}$ within the first $6 \mathrm{~h}$ after ROSC.

\section{Missing data}

The baseline data necessary to calculate each patient's baseline SOFA score were unavailable in the first $6 \mathrm{~h}$ in a small number of cases. In this situation, we used data within $12 \mathrm{~h}$ of the time of interest. When $\mathrm{PaO}_{2}$ data were unavailable even within $12 \mathrm{~h}$ of a given time point (3.2\% of cases), we calculated SOFA-R using peripheral oxygen saturation $\left(\mathrm{SpO}_{2}\right)$ which is recorded hourly based on the following table, which we developed on the basis of a previously validated $\mathrm{SpO}_{2}: \mathrm{FiO}_{2}$ estimation for $\mathrm{P}: \mathrm{F}$ ratio [28].

\section{Outcomes}

The primary outcomes of interest were the change in SOFA-R and dynamic pulmonary compliance over the first $48 \mathrm{~h}$ after admission, and second, the changes in SOFA-R and dynamic pulmonary compliance from 0 to $24 \mathrm{~h}$ and 0 to $72 \mathrm{~h}$. As lung injury develops over hours-to-days after the initial inflammatory or injurious insult, we chose these time points to ensure we fully captured the sequelae of the initial exposure [29]. Additional secondary outcomes of interest were 1) survival to hospital discharge, and 2) neurological outcomes, which we assessed by measuring the Pittsburgh cerebral performance category (CPC) at hospital discharge.

\section{Statistical analysis}

We used Stata Version 13.1 (StataCorp, College Station, TX, USA) for our analyses. We used linear regression to test the association between baseline characteristics and $\mathrm{FiO}_{2} \mathrm{AUC}$. Next, we explored the association between $\mathrm{FiO}_{2} \mathrm{AUC}$ and change in SOFA-R (using ordered logistic regression) and change in dynamic pulmonary compliance (using linear regression). Finally, we investigated the association between $\mathrm{FiO}_{2} \mathrm{AUC}$ and survival (using unadjusted and multiple logistic regression) and neurological outcome (using unadjusted and multiple ordered logistic regression). In the adjusted models we included only variables with unadjusted associations having outcomes with $P$-values $<0.2$, to avoid over-fitting. We confirmed the validity of the proportional odds assumption for ordered logistic regression test procedures. As a post hoc analysis, to determine whether baseline pulmonary dysfunction or change in pulmonary dysfunction differed between the in-hospital and out-of-hospital arrest populations, we stratified patients by arrest location and compared their baseline SOFA-R, dynamic pulmonary compliance and the change in these values from baseline to $72 \mathrm{~h}$ and 24 to $72 \mathrm{~h}$ using Fisher's exact tests and $t$-tests as appropriate.

To evaluate the possibility of a threshold effect for an association between oxygen exposure and clinical outcomes, we divided the population into quartiles based on $\mathrm{FiO}_{2} \mathrm{AUC}$ and compared survival and neurological outcome between these quartiles. Finally, to address the possibility of confounding by indication (that is, severity of illness may lead both to exposure to higher $\mathrm{FiO}_{2} \mathrm{AUC}$ and to worse outcomes in the absence of causality), we performed a propensity-adjusted analysis. We generated a saturated propensity score incorporating all baseline covariates to model the propensity for exposure to a higher quartile of $\mathrm{FiO}_{2} \mathrm{AUC}$ given baseline clinical characteristics, and then calculated the inverse probability of treatment weight (IPTW) using the inverse of the propensity score and a weight to reflect the sample size of each treatment group [30,31]. After checking for and removing any extreme outlier IPTW values, we constructed adjusted models using the IPTW to test for an independent association between $\mathrm{FiO}_{2} \mathrm{AUC}$ quartile and change in SOFA- $\mathrm{R}$ and dynamic pulmonary compliance from 0 to $48 \mathrm{~h}$, as well as overall survival.

\section{Results}

\section{Cohort characteristics}

Our initial registry query yielded 187 CA patients, of whom 17 were transferred from outlying facilities late in their post-arrest course and therefore excluded for missing post-ROSC ABG, vital sign or ventilator data based on our exclusion criteria, leaving 170 patients for analysis. Mean age was $60 \pm 6$ years and $52 \%$ were male (Table 1). The baseline $\mathrm{PaO}_{2}: \mathrm{FiO}_{2}$ ratio was $241 \pm 137$, and quantified using SOFA subscales, $85 \%$ of patients had baseline pulmonary failure while $55 \%$ had cardiovascular failure. Overall, pulmonary compliance and SOFA-R scores improved daily, with a mean change in SOFA-R of $-0.7 \pm 1.4$ and a mean change in dynamic pulmonary compliance of $3.8 \pm 18.4 \mathrm{~mL} / \mathrm{cmH}_{2} \mathrm{O}$ at $48 \mathrm{~h}$ (Table 2). Neither baseline measure of pulmonary dysfunction nor change from baseline to $72 \mathrm{~h}$ or change from 24 to $72 \mathrm{~h}$ differed across arrest location (data not shown). Patients with an initial arrest rhythm of VT/VF, lower initial $\mathrm{PaO}_{2}: \mathrm{FiO}_{2}$ ratio, and more severe shock were exposed to higher $\mathrm{FiO}_{2} \mathrm{AUCs}$ (Table 3).

\section{Pulmonary dysfunction}

In unadjusted analysis, $\mathrm{FiO}_{2} \mathrm{AUC}$ was not significantly associated with increased SOFA-R from 0 to $48 \mathrm{~h}$ (Table 4). No baseline predictors were associated with change in dynamic pulmonary compliance from 0 to $48 \mathrm{~h}$ (data not shown). In our adjusted model testing independent predictors of change in SOFA- $\mathrm{R}$ from 0 to $48 \mathrm{~h}, \mathrm{FiO}_{2}$ 
Table 1 Baseline population characteristics

\begin{tabular}{|c|c|c|c|}
\hline Characteristic & $\begin{array}{l}\text { Overall } \\
(n=170)\end{array}$ & $\begin{array}{l}\text { Non-survivors } \\
(\mathrm{n}=95)\end{array}$ & $\begin{array}{l}\text { Survivors } \\
(\mathrm{n}=75)\end{array}$ \\
\hline \multicolumn{4}{|l|}{ Demographics } \\
\hline Age, years & $60 \pm 16$ & $59 \pm 17$ & $63 \pm 15$ \\
\hline Male sex & $89(52 \%)$ & $54(61 \%)$ & $35(40 \%)$ \\
\hline \multicolumn{4}{|l|}{ Arrest characteristics } \\
\hline Out-of-hospital arrest & $96(56 \%)$ & $58(61 \%)$ & $38(51 \%)$ \\
\hline Initial rhythm VTNF & $64(38 \%)$ & $31(33 \%)$ & $33(44 \%)$ \\
\hline Therapeutic hypothermia used & $113(66 \%)$ & $76(80 \%)$ & 37 (49\%) \\
\hline \multicolumn{4}{|l|}{$\begin{array}{l}\text { Pittsburgh cardiac } \\
\text { arrest category }\end{array}$} \\
\hline 1 & $28(16 \%)$ & $9(9 \%)$ & $19(25 \%)$ \\
\hline 2 & $63(37 \%)$ & $26(27 \%)$ & $37(49 \%)$ \\
\hline 3 & $32(19 \%)$ & $19(20 \%)$ & $13(17 \%)$ \\
\hline 4 & $47(28 \%)$ & $41(43 \%)$ & $6(8 \%)$ \\
\hline \multicolumn{4}{|c|}{ Baseline physiologic and ventilator data } \\
\hline First $\mathrm{PaO}_{2}: \mathrm{FiO}_{2}$ ratio & $241 \pm 137$ & $249 \pm 129$ & $231 \pm 146$ \\
\hline $\begin{array}{l}\text { Dynamic compliance, } \\
\mathrm{mL} / \mathrm{cm} \mathrm{H} \mathrm{H}_{2} \mathrm{O}\end{array}$ & $29 \pm 12$ & $29 \pm 12$ & $28 \pm 13$ \\
\hline \multicolumn{4}{|l|}{ Initial SOFA-respiratory score } \\
\hline 0 & $26(15 \%)$ & $13(14 \%)$ & $13(17 \%)$ \\
\hline 1 & $33(19 \%)$ & $24(25 \%)$ & $9(12 \%)$ \\
\hline 2 & $33(19 \%)$ & $17(18 \%)$ & $16(21 \%)$ \\
\hline 3 & $46(27 \%)$ & $26(27 \%)$ & $20(27 \%)$ \\
\hline 4 & $32(19 \%)$ & $15(16 \%)$ & $17(23 \%)$ \\
\hline \multicolumn{4}{|l|}{ Initial SOFA-cardiovascular score } \\
\hline 0 & $76(45 \%)$ & $33(35 \%)$ & $43(57 \%)$ \\
\hline 1 & $18(11 \%)$ & $8(8 \%)$ & $10(13 \%)$ \\
\hline 2 & $10(6 \%)$ & $9(9 \%)$ & $1(1 \%)$ \\
\hline 3 & $31(18 \%)$ & $22(23 \%)$ & $9(12 \%)$ \\
\hline 4 & $25(21 \%)$ & $23(24 \%)$ & $12(16 \%)$ \\
\hline Cumulative vasopressor index & $1.4 \pm 1.9$ & $1.7 \pm 1.9$ & $1.1 \pm 1.9$ \\
\hline Time to first $\mathrm{FiO}_{2}$ wean, $\mathrm{h}$ & $6.3 \pm 6.4$ & $6.8 \pm 6.9$ & $5.8 \pm 5.6$ \\
\hline $\begin{array}{l}\text { Number of } \mathrm{FiO}_{2} \text { changes } \\
\text { in } 24 \mathrm{~h}\end{array}$ & $2.5 \pm 1.5$ & $2.5 \pm 1.6$ & $2.6 \pm 1.4$ \\
\hline
\end{tabular}

Data are presented as mean (standard deviation) or raw number with corresponding percentage. VTNF, ventricular tachycardia/fibrillation; $\mathrm{PaO}_{2}$, partial pressure of arterial oxygen; $\mathrm{FiO}_{2}$, fraction of inspired oxygen; SOFA, sequential organ failure assessment.

remained non-significant (odds ratio (OR) 0.96 (95\% confidence interval (CI) $0.88,1.04), P=0.34$ ).

\section{Secondary outcomes}

When we tested the association of $\mathrm{FiO}_{2} \mathrm{AUC}$ with outcomes, we found that in both unadjusted and adjusted analysis, higher $\mathrm{FiO}_{2} \mathrm{AUC}$ was associated with significantly lower odds of survival (Table 5) and worse $\mathrm{CPC}$ at hospital discharge (Additional file 1: Table S1
Table 2 Population physiological and neurological outcomes

\begin{tabular}{ll}
\hline Outcome & $\begin{array}{l}\text { Overall cohort } \\
\text { (n = 170) }\end{array}$ \\
\hline Change in SOFA-respiratory score & \\
0 to $24 \mathrm{~h}$ & $-0.3(1.5)$ \\
0 to $48 \mathrm{~h}$ & $-0.7(1.4)$ \\
0 to $72 \mathrm{~h}$ & $-0.9(1.5)$ \\
Change in lung compliance, $\mathrm{ml} / \mathrm{CmH}_{2} \mathrm{O}$ & \\
0 to $24 \mathrm{~h}$ & $0.5(13.9)$ \\
0 to $48 \mathrm{~h}$ & $3.8(18.4)$ \\
0 to $72 \mathrm{~h}$ & $4.9(21.0)$ \\
Discharge CPC & \\
1 & $8(5 \%)$ \\
2 & $1(1 \%)$ \\
3 & $58(34 \%)$ \\
4 & $7(4 \%)$ \\
5 & $94(56 \%)$ \\
Survival to hospital discharge & $75(44 \%)$
\end{tabular}

Data are presented as mean (standard deviation) or raw number with corresponding percentage. SOFA, sequential organ failure assessment; $C P C$ cerebral performance category.

and Additional file 2: Table S2). Although our model did not violate the assumption of proportional odds, stratifying patients by $\mathrm{FiO}_{2} \mathrm{AUC}$ quartile revealed that this effect on mortality was driven by lower survival among patients in the highest exposure quartile (OR for survival in the highest quartile compared to the lowest three quartiles 0.32 (95\% CI 0.13 to 0.79 ), $P=0.003$ ) (Figure 1).

\section{Propensity score-adjusted analysis}

The above findings were replicated in our propensity score-adjusted analysis, where only the highest quartile of $\mathrm{FiO}_{2} \mathrm{AUC}$ exposure was associated with increased mortality $(P=0.03)$. The change in SOFA-R and pulmonary compliance from 0 to $48 \mathrm{~h}$ did not differ between this quartile and the remaining three quartiles $(P=0.18$ and $P=0.39$, respectively). Compared to the other quartiles, the initial SOFA-R in this quartile was significantly higher (median SOFA-R $=3$ versus 1,2 and 2 in quartiles 1 to 3 , respectively; $P<0.001$ ). A propensity-adjusted analysis analyzing the affect of $\mathrm{FiO}_{2} \mathrm{AUC}$ on change in dynamic pulmonary compliance was not possible (terms were not uniquely estimable). In our propensity-adjusted analysis for change in SOFA- $\mathrm{R}$ from 0 to $48 \mathrm{~h}$, the highest quartile of $\mathrm{FiO}_{2} \mathrm{AUC}$ was associated with improved SOFA-R compared to the lowest quartile (OR 0.41, 95\% CI (0.19-0.88), $P=0.005)$ but there were no other significant differences in outcome across quartiles. 
Table 3 Unadjusted association between oxygen exposure over the first $24 \mathrm{~h}$ after $\mathrm{ROSC}\left(\mathrm{FIO}_{2} \mathrm{AUC}\right)$ and baseline arrest and cardiopulmonary characteristics

\begin{tabular}{|c|c|c|}
\hline Baseline predictor & B coefficient $(95 \% \mathrm{Cl})$ & $P$-value \\
\hline Age & $-0.035(-0.069$ to -0.001$)$ & 0.04 \\
\hline Male sex & $0.438(-0.658$ to 1.535$)$ & 0.43 \\
\hline Out-of-hospital arrest & $0.304(-0.802$ to 1.410$)$ & 0.59 \\
\hline Arrest rhythm VTNF & 1.306 (0.191 to 2.421) & 0.02 \\
\hline Received TH & $0.355(-0.806$ to 1.516$)$ & 0.55 \\
\hline \multicolumn{3}{|l|}{ PCAC } \\
\hline 1 & Reference & Reference \\
\hline 2 & $-0.246(-1.823$ to 1.332$)$ & 0.76 \\
\hline 3 & 2.346 (0.548 to 4.143 ) & 0.01 \\
\hline 4 & $0.441(-1.217$ to 2.100$)$ & 0.60 \\
\hline First P:F ratio per 25 & $-0.262(-0.354$ to -0.170$)$ & $<0.001$ \\
\hline Initial pulmonary compliance & $0.010(-0.035$ to 0.054$)$ & 0.67 \\
\hline \multicolumn{3}{|l|}{ Initial SOFA-respiratory score } \\
\hline 0 & Reference & Reference \\
\hline 1 & $1.246(-0.481$ to 2.973$)$ & 0.16 \\
\hline 2 & $1.703(-0.024$ to 3.430$)$ & 0.05 \\
\hline 3 & 3.431 (1.815 to 5.047$)$ & $<0.001$ \\
\hline 4 & 4.279 (2.540 to 6.018$)$ & $<0.001$ \\
\hline \multicolumn{3}{|l|}{ Initial SOFA-cardiovascular score } \\
\hline 0 & Reference & Reference \\
\hline 1 & $-1.190(-3.040$ to 0.660$)$ & 0.21 \\
\hline 2 & $0.145(-2.230$ to 2.519$)$ & 0.90 \\
\hline 3 & $1.092(-2.230$ to 2.600$)$ & 0.15 \\
\hline 4 & $1.245(-0.197$ to 2.686$)$ & 0.09 \\
\hline Initial cardiovascular index & 0.346 (0.061 to 0.630$)$ & 0.02 \\
\hline Time to first $\mathrm{FiO}_{2}$ wean & $0.012(-0.074$ to 0.099$)$ & 0.78 \\
\hline Number of $\mathrm{FiO}_{2}$ changes in $24 \mathrm{~h}$ & $-0.076(-0.436$ to 0.283$)$ & 0.68 \\
\hline
\end{tabular}

$V T N F$, ventricular tachycardia/ventricular fibrillation; $T H$, therapeutic hypothermia; $P C A C$, Pittsburgh cardiac arrest category; P:F, ratio of partial pressure of arterial oxygen $\left(\mathrm{PaO}_{2}\right)$ to fraction of inspired oxygen $\left(\mathrm{FiO}_{2}\right)$; SOFA, sequential organ failure assessment.

\section{Discussion}

We examined the association between inhaled oxygen exposure and change in pulmonary function after CA. Higher oxygen exposure in the initial $24 \mathrm{~h}$ was strongly associated with the presence of baseline cardiopulmonary dysfunction, but was not associated with deterioration in pulmonary compliance or gas exchange in the first $48 \mathrm{~h}$ after ROSC. In fact, in our propensity-adjusted analysis, CA patients in the highest quartile of oxygen exposure had improved lung function compared to the lowest quartile of exposure. Despite the absence of an association with change in lung function, higher inhaled oxygen levels were independently associated with decreased survival and worse neurological
Table 4 Unadjusted odds of change in the respiratory subscale of the Sequential Organ Failure Assessment score from 0 to $48 \mathrm{~h}$

\begin{tabular}{|c|c|c|}
\hline Predictor & $\begin{array}{l}\text { Unadjusted odds } \\
\text { ratio* }(95 \% \mathrm{Cl})\end{array}$ & $P$-value \\
\hline $\mathrm{FiO}_{2} \mathrm{AUC}$ & 0.93 (0.86 to 1.02$)$ & 0.11 \\
\hline Age & $1.00(0.98$ to 1.02$)$ & 0.86 \\
\hline Male sex & 1.11 (0.62 to 2.00$)$ & 0.72 \\
\hline Out-of-hospital arrest & 2.02 (1.11 to 3.67$)$ & 0.02 \\
\hline Arrest rhythm VTNF & 1.09 (0.78 to 2.00$)$ & 0.78 \\
\hline Received TH & 2.74 (1.43 to 5.25$)$ & $<0.01$ \\
\hline \multicolumn{3}{|l|}{ PCAC } \\
\hline 1 & Reference & Reference \\
\hline 2 & 2.24 (0.88 to 5.70$)$ & 0.09 \\
\hline 3 & 0.87 (0.32 to 2.42$)$ & 0.80 \\
\hline 4 & 2.58 (0.97 to 6.84$)$ & 0.06 \\
\hline Initial pulmonary compliance & 0.98 (0.95 to 1.01$)$ & 0.24 \\
\hline \multicolumn{3}{|l|}{ Initial SOFA-cardiovascular score } \\
\hline 0 & Reference & Reference \\
\hline 1 & $0.71(0.27$ to 1.85$)$ & 0.48 \\
\hline 2 & 1.88 (0.50 to 7.04$)$ & 0.35 \\
\hline 3 & 2.11 (0.93 to 4.77 ) & 0.07 \\
\hline 4 & 1.02 (0.47 to 2.24$)$ & 0.96 \\
\hline Initial CVI & 1.04 (0.90 to 1.20$)$ & 0.62 \\
\hline Time to first $\mathrm{FiO}_{2}$ wean & 0.99 (0.95 to 1.03$)$ & 0.67 \\
\hline Number of $\mathrm{FiO}_{2}$ changes in $24 \mathrm{~h}$ & 0.82 (0.68 to 0.99$)$ & 0.04 \\
\hline
\end{tabular}

${ }^{*}$ Odds ratios are presented per unit increase in respiratory subscale score. $\mathrm{FiO}_{2}$, fraction of inspired oxygen; AUC, area under the curve; VT/VF, ventricular tachycardia or ventricular fibrillation; $\mathrm{TH}$, therapeutic hypothermia; PCAC, Pittsburgh cardiac arrest category; SOFA, sequential organ failure assessment; CVI, cumulative vasopressor index.

outcomes. Taken together, these data suggest that pulmonary oxygen toxicity is not a clinically important mediator of the association between hyperoxia and patient outcomes after CA.

A study of the Project IMPACT database found an association between arterial hyperoxia and worsened survival after CA [8]. The same authors reported increasing odds of mortality in a linear fashion for $\mathrm{PaO}_{2}$ values in excess of $100 \mathrm{mmHg}$, suggestive of dose-dependent toxicity [9]. A significant limitation of this work was the use of a single marker of hyperoxemia (that is, first $\mathrm{PaO}_{2}$ ) without regard to underlying physiologic dysfunction and without assessment of subsequent time points. Furthermore, other large database studies have failed to reproduce this finding $[32,33]$. Unlike those prior, we have incorporated not only physiologic measures of baseline lung diffusion and cardiac function into our models, expanded our analysis beyond the initial or highest level of oxygenation, and controlled for the appropriate tendency of 
Table 5 Unadjusted and adjusted associations between predictors and odds of survival to hospital discharge

Baseline predictor
$\mathrm{FiO}_{2} \mathrm{AUC}$
$\mathrm{Age}$
Male sex
Out-of-hospital arrest
Arrest rhythm VTNF
Received TH
PCAC
1
2
3
4

First P:F ratio

Initial pulmonary compliance

Initial SOFA-respiratory score

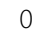

2

2

3

4

Initial SOFA-cardiovascular score

0

1

2

3

4

Initial CVI

Time to first vent wean

Number of vent weans in $24 \mathrm{~h}$

$\mathrm{FiO} 2 \mathrm{AUC}$

Age

Male sex

Out-of-hospital arrest

Arrest rhythm VTNF

Received TH

PCAC

1

2

3

4

Initial SOFA-cardiovascular score

0

Odds ratio (OR) $P$-value

Unadjusted OR $(95 \% \mathrm{Cl})$

0.90 (0.82 to 0.98 )

0.02

1.02 (1.00 to 1.04 )

0.66 (0.19 to 1.22$)$

0.66 (0.36 to 1.21$)$

1.62 (0.87 to 3.03 )

0.24 (0.13 to 0.48 )

Reference

0.67 (0.26 to 1.72 )

0.32 (0.11 to 0.94 )

0.07 (0.02 to 0.22$)$

1.00 (1.00 to 1.00 )

0.99 (0.97 to 1.02 )

Reference

0.38 (0.13 to 1.11)

0.94 (0.34 to 2.63 )

0.77 (0.29 to 2.02)

1.13 (0.40 to 3.19$)$

Reference

0.95 (0.34 to 2.70)

0.09 (0.01 to 0.71 )

0.31 (0.13 to 0.77 )

0.40 (0.17 to 0.92 )

0.82 (0.69 to 0.98 )

1.04 (1.00 to 1.10 )

0.79 (0.64 to 0.98 )

Adjusted OR $(95 \% \mathrm{Cl})$

0.86 (0.76 to 0.97 )

1.01 (0.98 to 1.04 )

0.52 (0.23 to 1.18 )

1.48 (0.52 to 4.23 )

1.53 (0.62 to 3.77 )

0.19 (0.07 to 0.58$)$

Reference

1.25 (0.33 to 4.79)

0.91 (0.24 to 3.51 )

0.13 (0.03 to 0.58 )

Reference

0.04

$<0.001$

0.38

0.68

0.23

0.08

0.91

0.59

0.81

$<0.01$

0.94

0.02

0.01

0.03

0.03

0.08

0.03

0.02

0.38

0.12

0.46

0.35

$<0.01$

0.74

0.89

$<0.01$
Table 5 Unadjusted and adjusted associations between predictors and odds of survival to hospital discharge (Continued)

\begin{tabular}{ccc}
\hline 1 & $0.62(0.14$ to 2.69$)$ & 0.52 \\
2 & $0.05(0.00$ to 0.71$)$ & 0.03 \\
3 & $0.23(0.04$ to 1.31$)$ & 0.10 \\
4 & $0.12(0.01$ to 1.73$)$ & 0.12 \\
Initial CVI & $1.29(0.73$ to 2.26$)$ & 0.38 \\
Time to first vent wean & $0.78(0.95$ to 1.10$)$ & 0.13 \\
Number of vent weans in $24 \mathrm{~h}$ & $1.03(0.58$ to 1.07$)$ & 0.49 \\
\hline
\end{tabular}

$\mathrm{FiO}_{2}$, fraction of inspired oxygen; $A U$, area under the curve; VTNF, ventricular tachycardia or ventricular fibrillation; $T H$, therapeutic hypothermia; $P C A C$,

Pittsburgh cardiac arrest category; $P: F$, partial pressure of arterial oxygen to fraction of inspired oxygen; SOFA, sequential organ failure assessment; CVI, cumulative vasopressor index.

Reference

Reference

Reference

Reference clinicians to increase $\mathrm{FiO}_{2}$ in patients with more severe cardiopulmonary dysfunction.

Our study also differs from previous work in that it examines both surrogate endpoints of pulmonary dysfunction as well as clinically meaningful endpoints. Our results reflect that oxygen exposure was increased in those with the worst early cardiopulmonary dysfunction, which one would expect if oxygen were being titrated based on the clinical assessment of the patient. There was no association between the time to first $\mathrm{FiO}_{2}$ wean or the total number of adjustments made in $24 \mathrm{~h}$, suggesting that higher $\mathrm{FiO}_{2} \mathrm{AUC}$ is not a surrogate marker for less attentive care. The correlation between oxygen exposure and SOFA- $\mathrm{R}$, which is based on the $\mathrm{PaO}_{2}: \mathrm{FiO}_{2}$ ratio, is consistent with the appropriate dosing of patients with reduced oxygen diffusive capacity with higher inspired oxygen. The loss of association when comparing early oxygen exposure to subsequent changes in measures of pulmonary dysfunction (SOFA-R or compliance) is contradictory to the notion that early oxygen toxicity results in subsequent lung injury.

Importantly, despite observing no association between oxygen exposure and pulmonary dysfunction, we observed significantly worse survival in the quartile of CA patients with the highest oxygen exposure (25\% versus $50 \%$, $P=0.003)$, which remained significant in adjusted analysis and in our propensity-adjusted analysis. This may be explained by the fact that this quartile had the highest baseline SOFA- $R$ scores and may have been sicker than the other quartiles. However, this excess mortality is also consistent with the findings from the Project IMPACT database, although we did not observe a linear dose-response curve as they did. Rather, we observed what appears to be a threshold effect where toxicity accrued only after $\mathrm{FiO}_{2}$ exceeded an average of 0.75 over $24 \mathrm{~h}$. If oxidative stress after CA worsens outcomes [34-36] then it is likely that neuronal injury, rather than pulmonary toxicity, drives this effect. Indeed, 


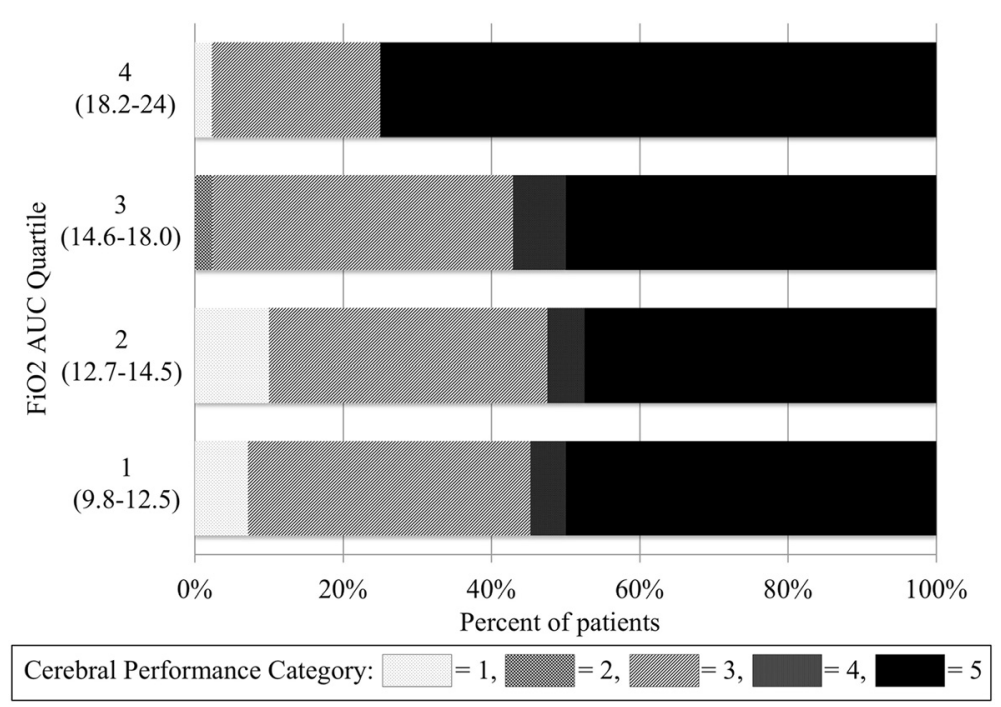

Figure 1 Cerebral performance category stratified by quartile of fraction of inspired oxygen area under the curve (FiO $\mathrm{AUC}_{2}$.

brain injury is the largest contributor to death after CA [37], though pulmonary dysfunction may play a role, particularly after in-hospital CA [24]. We hypothesize that the threshold for toxicity we observed occurs at the level of exposure at which oxidative stress exceeds antioxidant reserves. Thus, it may be most desirable to decrease $\mathrm{FiO}_{2}$ in patients receiving the highest oxygen exposure. Though this would seem intuitive, a recent report revealed that as many as $18 \%$ of hyperoxic patients receiving $\mathrm{FiO}_{2}>0.80$ have neither their $\mathrm{FiO}_{2}$ nor their PEEP weaned [38].

There are limitations to our study, which are common to retrospective observational studies. Because patients in our study were not randomized, we cannot determine causality. A significant concern in this type of observational study is confounding by indication, whereby sicker patients may also be at higher risk of oxygen exposure, whether appropriate or inappropriate, due to their severity of illness. Propensity-adjusted analysis may partially control for this phenomenon, and our propensity-adjusted analysis for survival replicated our findings. Moreover, in the same propensity-adjusted analysis, those patients in the highest quartile of oxygen exposure had improved lung function over $24 \mathrm{~h}$ compared to those in the lowest quartile of exposure, further strengthening our assertion that pulmonary oxygen toxicity is not a clinically relevant phenomenon in this patient population. We believe a randomized study would be difficult to perform ethically with the present concerns over hyperoxia after CA, so well-adjusted observational studies are the highest level of evidence possible. Furthermore, our outcome measures (change in SOFA-R and dynamic pulmonary compliance) do not fully represent change in lung dysfunction or the potential for pulmonary oxygen toxicity. There are no compelling data to suggest whether compliance or oxygenation is a better measure of lung dysfunction. As P:F ratio is commonly used in studies of acute lung injury, and previous animal studies have used pulmonary dynamic compliance as a measure of lung function $[39,40]$, we chose to measure both. However, it is important to note that P:F ratio can vary across $\mathrm{FiO}_{2}$ irrespective of changes in pulmonary function [41], and post-arrest patients often have significant changes made in $\mathrm{FiO}_{2}$ in the first $24 \mathrm{~h}$ after ROSC [10]. We believe that we chose the two best measures of lung dysfunction that can be obtained in an observational clinical study, but they are nevertheless imperfect.

Since our work was retrospective, we did not perform a power calculation a priori, and unfortunately post hoc power calculations have little statistical meaning or utility [42], but our main findings may have resulted from a type II error. Additionally, the observational nature of our study means that our blood gases were not all collected at standardized times and so we were forced to estimate $\mathrm{PaO}_{2}: \mathrm{FiO}_{2}$ ratios and SOFA- $\mathrm{R}$ scores using either closely timed blood gases or pulse oximetry data. Further, by limiting our analysis to CA patients who survived and were ventilated $\geq 24 \mathrm{~h}$, we excluded both the sickest and the healthiest post-arrest patients. Patients who are extubated within $24 \mathrm{~h}$ after a CA generally have very good outcomes while withdrawal of care within $24 \mathrm{~h}$ is generally due to extremely grim prognosis. By excluding these patients, our analysis may exaggerate the magnitude of the association between oxygen exposure and mortality. 


\section{Conclusion}

Our findings suggest that high levels of inhaled oxygen are not associated with deterioration in gas exchange or pulmonary compliance after cardiac arrest. However, oxygen exposure was associated with decreased survival to discharge and worse neurological outcomes. Taken together, it does not appear that pulmonary oxygen toxicity mediates the association between hyperoxia and poor outcomes after cardiac arrest.

\section{Key messages}

- Post-arrest patients are often exposed to $100 \%$ oxygen during cardiopulmonary resuscitation and the post-arrest period, raising concern for the potential for pulmonary oxygen toxicity.

- This study suggests that higher oxygen exposure is not associated with subsequent pulmonary dysfunction after cardiac arrest.

- At extreme levels, high oxygen exposure was associated with decreased survival to discharge, probably related to worsened neurological injury.

- We suggest avoiding prolonged exposure to a FiO2 $>0.75$ in the early post-arrest period unless necessary to prevent hypoxia.

\section{Additional files}

\section{Additional file 1: Table S1. Unadjusted associations between}

exposures and discharge cerebral performance category. Abbreviations: $\mathrm{FiO} 2$ - Fraction of inspired oxygen; AUC - Area under the curve; VTNF - Ventricular tachycardia or ventricular fibrillation; TH - Therapeutic hypothermia; PCAC - Pittsburgh Cardiac Arrest Category; P:F - Partial pressure of arterial oxygen to fraction of inspired oxygen; SOFA - Sequential Organ Failure Assessment; CVI - Cumulative vasopressor index; OR - Odds ratio.

Additional file 2: Table S2. Adjusted associations between exposures and discharge cerebral performance category. Abbreviations: $\mathrm{FiO} 2$ - Fraction of inspired oxygen; AUC - Area under the curve; VTNF - Ventricular tachycardia or ventricular fibrillation; TH - Therapeutic hypothermia; PCAC - Pittsburgh Cardiac Arrest Category; SOFA Sequential Organ Failure Assessment; CVl - Cumulative vasopressor index; OR - Odds ratio.

\section{Abbreviations}

ARDS: acute respiratory distress syndrome; AUC: area under the curve; CA: cardiac arrest; CPC: Pittsburgh cerebral performance category; CPR: cardiopulmonary resuscitation; CVl: cardiovascular index; FiO2: fraction of inspired oxygen; $\mathrm{FiO}_{2} \mathrm{AUC}$ : area under the curve of the fraction of inspired oxygen for each patient over 24 h; IPTW: inverse probability of treatment weight; MAP: mean arterial pressure; $\mathrm{PaO} 2$ : partial pressure of arterial oxygen; PCAC: Pittsburgh cardiac arrest category; PCAS: Pittsburgh post-cardiac arrest service; PEA: pulseless electrical activity; PEEP: positive end-expiratory pressure; ROSC: return of spontaneous circulation; SOFA: sequential organ failure assessment score; SOFA-CV: cardiovascular subscale of the sequential organ failure assessment score; SOFA-R: respiratory subscale of the sequential organ failure assessment score; VTNF: ventricular tachycardia or fibrillation.
}

\section{Competing interests}

The authors declare that they have no competing interests.

\section{Authors' contributions}

JE assisted with data acquisition, statistical analysis, and data interpretation, and drafted the manuscript. BW, SM, RP, NV and JB participated in the design of the study, substantially contributed to data acquisition and provided critical revisions to the manuscript. BR performed portions of the statistical analysis and assisted with data interpretation. AAD and CWC substantially contributed to analysis and interpretation of the data, and provided critical revisions to the manuscript. CD conceived of the study, substantially contributed to analysis and interpretation of the data, and provided critical revisions to the manuscript. All authors read and approved the manuscript in its final version and agree to be accountable for all aspects of the work including its accuracy and integrity.

\section{Authors' information}

Appendix: The Pittsburgh Post-Cardiac Arrest Service investigators: Clifton W. Callaway, Cameron Dezfulian, Ankur A. Doshi, Jonathan Elmer, Francis X. Guyette, and Jon C. Rittenberger.

\section{Acknowledgements}

Dr Dezfulian's research time is supported by the NHLBI K08NS069817.

Dr Elmer's research time is supported by the NHLBI 5K12HL109068.

Dr Rosario's time is supported by the NIH CTSA program grant UL1TR000005.

\section{Author details}

'Safar Center for Resuscitation Research, University of Pittsburgh School of Medicine, 100 Hill Building, 3434 Fifth Avenue, Pittsburgh, PA 15260, USA. ${ }^{2}$ Department of Critical Care Medicine, University of Pittsburgh School of Medicine, Pittsburgh, USA. ${ }^{3}$ Department of Emergency Medicine, University of Pittsburgh School of Medicine, Pittsburgh, USA. ${ }^{4}$ Department of Anesthesiology, New York University Langone Medical Center, Pittsburgh, USA. ${ }^{5}$ Department of Internal Medicine, University of Pittsburgh Medical Center Mercy Hospital, Pittsburgh, USA. ${ }^{6}$ Department of Epidemiology, Graduate School of Public Health, University of Pittsburgh, Pittsburgh, USA. ${ }^{7}$ Vascular Medicine Institute, University of Pittsburgh School of Medicine, Pittsburgh, USA.

Received: 6 October 2014 Accepted: 19 February 2015

Published online: 10 March 2015

\section{References}

1. Roger VL, Go AS, Lloyd-Jones DM, Benjamin EJ, Berry JD, Borden WB, et al. Heart disease and stroke statistics-2012 update: a report from the American Heart Association. Circulation. 2012;125(1):e2-220. doi:10.1161/CIR.0b013e31823ac046.

2. Peberdy MA, Kaye W, Ornato JP, Larkin GL, Nadkarni V, Mancini ME, et al. Cardiopulmonary resuscitation of adults in the hospital: a report of 14720 cardiac arrests from the National Registry of Cardiopulmonary Resuscitation. Resuscitation. 2003;58(3):297-308.

3. Stiell IG, Wells GA, Field B, Spaite DW, Nesbitt LP, De Maio VJ, et al. Advanced cardiac life support in out-of-hospital cardiac arrest. N Engl J Med. 2004;351(7):647-56. doi:10.1056/NEJMoa040325.

4. Negovsky VA. The second step in resuscitation-the treatment of the 'post-resuscitation disease'. Resuscitation. 1972;1(1):1-7.

5. Neumar RW, Nolan JP, Adrie C, Aibiki M, Berg RA, Bottiger BW, et al. Post-cardiac arrest syndrome: epidemiology, pathophysiology, treatment, and prognostication. A consensus statement from the International Liaison Committee on Resuscitation (American Heart Association, Australian and New Zealand Council on Resuscitation, European Resuscitation Council, Heart and Stroke Foundation of Canada, InterAmerican Heart Foundation, Resuscitation Council of Asia, and the Resuscitation Council of Southern Africa); the American Heart Association Emergency Cardiovascular Care Committee; the Council on Cardiovascular Surgery and Anesthesia; the Council on Cardiopulmonary, Perioperative, and Critical Care; the Council on Clinical Cardiology; and the Stroke Council. Circulation. 2008;118(23):2452-83. doi:10.1161/CIRCULATIONAHA.108.190652.

6. Negovsky VA. Postresuscitation disease. Crit Care Med. 1988;16(10):942-6.

7. Ferguson LP, Durward A, Tibby SM. Relationship between arterial partial oxygen pressure after resuscitation from cardiac arrest and mortality in children. Circulation. 2012;126(3):335-42. doi:10.1161/ CIRCULATIONAHA.111.085100.

8. Kilgannon JH, Jones AE, Shapiro NI, Angelos MG, Milcarek B, Hunter K, et al Association between arterial hyperoxia following resuscitation from 
cardiac arrest and in-hospital mortality. JAMA. 2010;303(21):2165-71. doi:10.1001/jama.2010.707.

9. Kilgannon JH, Jones AE, Parrillo JE, Dellinger RP, Milcarek B, Hunter K, et al. Relationship between supranormal oxygen tension and outcome after resuscitation from cardiac arrest. Circulation. 2011;123(23):2717-22. doi:10.1161/CIRCULATIONAHA.110.001016.

10. Elmer J, Scutella M, Pullalarevu R, Wang B, Vaghasia N, Trzeciak S, et al. The association between hyperoxia and patient outcomes after cardiac arrest: analysis of a high-resolution database. Intensive Care Med. 2015;41(1):49-57. doi:10.1007/s00134-014-3555-6.

11. Pagano A, Barazzone-Argiroffo C. Alveolar cell death in hyperoxia-induced lung injury. Ann NY Acad Sci. 2003;1010:405-16.

12. Bhandari V. Molecular mechanisms of hyperoxia-induced acute lung injury. Front Biosci. 2008;13:6653-61.

13. Peberdy MA, Callaway CW, Neumar RW, Geocadin RG, Zimmerman JL, Donnino M, et al. Part 9: post-cardiac arrest care: 2010 American Heart Association Guidelines for Cardiopulmonary Resuscitation and Emergency Cardiovascular Care. Circulation. 2010;122(18 Suppl 3):S768-86. doi:10.1161/ CIRCULATIONAHA. 110.971002.

14. Matute-Bello G, Frevert CW, Martin TR. Animal models of acute lung injury. Am J Physiol Lung Cell Mol Physiol. 2008;295(3):L379-99. doi:10.1152/ ajplung.00010.2008.

15. Altemeier WA, Sinclair SE. Hyperoxia in the intensive care unit: why more is not always better. Curr Opin Crit Care. 2007;13(1):73-8. doi:10.1097/ MCC.0b013e32801162cb.

16. De Paepe ME, Mao Q, Chao Y, Powell JL, Rubin LP, Sharma S. Hyperoxia-induced apoptosis and Fas/FasL expression in lung epithelial cells. Am J Physiol Lung Cell Mol Physiol. 2005;289(4):L647-59. doi:10.1152/ajplung.00445.2004.

17. He CH, Waxman AB, Lee CG, Link H, Rabach ME, Ma B, et al. Bcl-2-related protein $\mathrm{A} 1$ is an endogenous and cytokine-stimulated mediator of cytoprotection in hyperoxic acute lung injury. J Clin Invest. 2005;115(4):1039-48. doi:10.1172/JCI23004.

18. Sinclair SE, Altemeier WA, Matute-Bello G, Chi EY. Augmented lung injury due to interaction between hyperoxia and mechanical ventilation. Crit Care Med. 2004;32(12):2496-501.

19. Liu YY, Liao SK, Huang CC, Tsai YH, Quinn DA, Li LF. Role for nuclear factor-kappaB in augmented lung injury because of interaction between hyperoxia and high stretch ventilation. Transl Res. 2009;154(5):228-40. doi:10.1016/j.trsl.2009.06.006.

20. Barber RE, Hamilton WK. Oxygen toxicity in man. N Engl J Med. 1970;283 (27):1478-84. doi:10.1056/NEJM197012312832702.

21. Kapanci Y, Tosco R, Eggermann J, Gould VE. Oxygen pneumonitis in man., Light- and electron-microscopic morphometric studies. Chest. 1972;62(2):162-9.

22. Nash G, Blennerhassett J, Pontoppidan H. Pulmonary lesions associated with oxygen therapy and artificial ventilation. Laval Med. 1968;39(1):59-64.

23. Rittenberger JC, Tisherman SA, Holm MB, Guyette FX, Callaway CW. An early, novel illness severity score to predict outcome after cardiac arrest. Resuscitation. 2011;82(11):1399-404. doi:10.1016/j.resuscitation.2011.06.024.

24. Roberts BW, Kilgannon JH, Chansky ME, Mittal N, Wooden J, Parrillo JE, et al. Multiple organ dysfunction after return of spontaneous circulation in postcardiac arrest syndrome. Crit Care Med. 2013;41(6):1492-501. doi:10.1097/CCM.0b013e31828a39e9.

25. Rittenberger JC, Guyette FX, Tisherman SA, DeVita MA, Alvarez RJ, Callaway CW. Outcomes of a hospital-wide plan to improve care of comatose survivors of cardiac arrest. Resuscitation. 2008;79(2):198-204. doi:10.1016/j. resuscitation.2008.08.014.

26. Vincent JL, Moreno R, Takala J, Willatts S, De Mendonca A, Bruining H, et al. The SOFA (Sepsis-related Organ Failure Assessment) score to describe organ dysfunction/failure. On behalf of the Working Group on Sepsis-Related Problems of the European Society of Intensive Care Medicine. Intensive Care Med. 1996;22(7):707-10.

27. Trzeciak S, McCoy JV, Phillip Dellinger R, Arnold RC, Rizzuto M, Abate NL, et al. Early increases in microcirculatory perfusion during protocol-directed resuscitation are associated with reduced multi-organ failure at $24 \mathrm{~h}$ in patients with sepsis. Intensive Care Med. 2008;34(12):2210-7. doi:10.1007/ s00134-008-1193-6.

28. Pandharipande PP, Shintani AK, Hagerman HE, St Jacques PJ, Rice TW, Sanders NW, et al. Derivation and validation of Spo2/Fio2 ratio to impute for Pao2/Fio2 ratio in the respiratory component of the Sequential Organ
Failure Assessment score. Crit Care Med. 2009;37(4):1317-21. doi:0.1097/ CCM.0b013e31819cefa9.

29. Johnson ER, Matthay MA. Acute lung injury: epidemiology, pathogenesis, and treatment. J Aerosol Med Pulm Drug Deliv. 2010;23(4):243-52. doi:10.1089/jamp.2009.0775.

30. Harder VS, Stuart EA, Anthony JC. Propensity score techniques and the assessment of measured covariate balance to test causal associations in psychological research. Psychol Methods. 2010;15(3):234-49. doi:10.1037/ a0019623.

31. Robins JM, Hernan MA, Brumback B. Marginal structural models and causal inference in epidemiology. Epidemiology. 2000;11(5):550-60.

32. Ihle JF, Bernard S, Bailey MJ, Pilcher DV, Smith K, Scheinkestel CD. Hyperoxia in the intensive care unit and outcome after out-of-hospital ventricular fibrillation cardiac arrest. Crit Care Resusc. 2013;15(3):186-90.

33. Bellomo R, Bailey M, Eastwood GM, Nichol A, Pilcher D, Hart GK, et al. Arterial hyperoxia and in-hospital mortality after resuscitation from cardiac arrest. Crit Care. 2011;15(2):R90. doi:10.1186/cc10090.

34. Dohi K, Miyamoto K, Fukuda K, Nakamura S, Hayashi M, Ohtaki H, et al. Status of systemic oxidative stress during therapeutic hypothermia in patients with post-cardiac arrest syndrome. Oxidative Med Cell Longev. 2013;2013:562429. doi:10.1155/2013/562429.

35. Liu Y, Rosenthal RE, Haywood Y, Miljkovic-Lolic M, Vanderhoek JY, Fiskum G. Normoxic ventilation after cardiac arrest reduces oxidation of brain lipids and improves neurological outcome. Stroke. 1998;29(8):1679-86.

36. Vereczki V, Martin E, Rosenthal RE, Hof PR, Hoffman GE, Fiskum G. Normoxic resuscitation after cardiac arrest protects against hippocampal oxidative stress, metabolic dysfunction, and neuronal death. J Cereb Blood Flow Metab. 2006;26(6):821-35. doi:10.1038/sj.jcbfm.9600234.

37. Laver S, Farrow C, Turner D, Nolan J. Mode of death after admission to an intensive care unit following cardiac arrest. Intensive Care Med. 2004;30(11):2126-8. doi:10.1007/s00134-004-2425-z.

38. de Graaff AE, Dongelmans DA, Binnekade JM, de Jonge E. Clinicians' response to hyperoxia in ventilated patients in a Dutch ICU depends on the level of FiO2. Intensive Care Med. 2011;37(1):46-51. doi:10.1007/s00134-010-2025-z.

39. Clark WT, Jones BR, Clark J. Dynamic pulmonary compliance as a measurement of lung function in dogs. Vet Rec. 1977;101(25):497-9.

40. Martin TR, Gerard NP, Galli SJ, Drazen JM. Pulmonary responses to bronchoconstrictor agonists in the mouse. J Appl Physiol. 1988;64(6):2318-23.

41. Allardet-Servent J, Forel JM, Roch A, Guervilly C, Chiche L, Castanier M, et al. $\mathrm{FIO} 2$ and acute respiratory distress syndrome definition during lung protective ventilation. Crit Care Med. 2009;37(1):202-7. e4-6. doi:10.1097/ CCM.0b013e31819261db.

42. Hoenig JM, Heisey DM. The abuse of power: The pervasive fallacy of power calculations for data analysis. Am Stat. 2001;55(1):19-24. doi: 10.1198/ 000313001300339897.

\section{Submit your next manuscript to BioMed Central and take full advantage of:}

- Convenient online submission

- Thorough peer review

- No space constraints or color figure charges

- Immediate publication on acceptance

- Inclusion in PubMed, CAS, Scopus and Google Scholar

- Research which is freely available for redistribution

Submit your manuscript at www.biomedcentral.com/submit

C Biomed Central 